\title{
Exploring the Role and Contribution of Police Support Volunteers (PSV) in an English Constabulary
}

Melissa Pepper (University of Greenwich), Karen Bullock and Dan McCarthy (University of Surrey)

\begin{abstract}
Police Support Volunteers (PSVs) - citizens who give their time freely to perform tasks that complement the duties of officers and staff - undertake a variety of roles across every police service in England and Wales. PSVs offer additional capacity to policing, as well as opportunities for enhanced service delivery. PSVs attach considerable meaning to their contribution, and this is found to be instrumental to motivation, satisfaction, and intention to continue. However, creating meaningful opportunities for PSVs is challenging: they are welcome donors of time and skills, but must remain non-essential. Drawing on a survey of 140 PSVs in a large urban constabulary in England, this article considers the contribution of PSVs, exploring findings through two typologies (motivation and role type), and highlighting the importance of feeling and being 'useful'. The article calls for a more imaginative stance to involving PSVs at a time of shifting priorities and diminishing resources.
\end{abstract}

\section{Introduction}

This article considers the role and contribution of Police Support Volunteers (PSVs) - citizens who give their time freely to perform tasks that complement the duties of police officers and staff - in an English constabulary. It draws on two PSV typologies - motivation (The Altruistic PSV, The Social PSV and The Career PSV) and role (The Operational PSV and The NonOperational PSV) to explore PSVs' perceptions of their contribution: a 'one size fits all' process, or experiences that are more multi-dimensional, with factors related to individuals' roles, tasks, and motivations impacting on the 'service' they feel able to offer, satisfaction 
within their role, and their intention to continue to give their time to policing. The article concludes with a discussion of the PSV against the backdrop of a rapidly shifting police landscape, and points to their position in a re-shaped policing climate.

The research comes at an important time in the development of PSVs. The changing shape of policing, with increasingly complex tasks, reducing budgets, and pluralising workforces, coupled with opportunities to extend volunteer powers set out in the Policing and Crime Act 2017, arguably points to increasing prominence for PSVs going forward. However, capitalising on the benefits that PSVs can bring (engagement, communication, innovation, and a source of skills and expertise) requires a more developed understanding of the role of volunteers in policing. This article contributes to an evidence base that is strikingly under developed in its current form, offering new directions in policy and practice.

\section{Background}

While volunteers - most notably the Special Constable - are a familiar presence in policing, PSVs are a relatively new addition, emerging in forces throughout England and Wales from the 1990s onwards (Bullock, 2014; Millie, 2019). There are currently around 8,265 PSVs in England and Wales, undertaking over 1,100 different roles from administration and front counter duties, to community engagement activities, operational functions including traffic speed checks and viewing CCTV footage, and specialist skill or interest roles such as scientific support, gardening, and equine assistance (IPSCJ, 2018).

The roles that volunteers undertake and the contribution they feel able to make are influential on volunteer experiences and have been recognised as significant enablers or inhibitors of sustained volunteerism more broadly (Penner, 2002). This is echoed in the limited studies 
focusing on police volunteers which underline the influence of meaningful deployment on volunteer morale, sense of value, and retention (Whittle, 2014; Callender et al., 2018a). However, PSVs have been met with cynicism within the police, especially regarding job cuts amongst the paid workforce (Unison, 2014, 2018; van Steden and Mehlbaum, 2019). With the climate of austerity continuing to impact police resources (National Audit Office, 2018), debates exist about how far PSVs reflect additions or substitutions to police roles. This has implications for the PSV contribution, and the extent to which PSVs are supported and integrated within the police service (Britton and Callender, 2018; Callender et al., 2019).

\section{Literature review}

\section{Understanding the PSV Contribution}

The tasks that volunteers in policing undertake have been shown to be wide ranging, covering the spectrum of police responsibilities: crime prevention, maintaining public order, improving detections, victim services, developing a sense of community ownership and inclusion, encouraging greater transparency, and promoting a better flow of information between police and citizens (Ren et al., 2006; Gravelle and Rogers, 2009; Steden et al., 2011; Morgan, 2012). A range of studies (e.g., Brudney and Kellough, 2000; Choudhury, 2010; Larson et al., 2011; Clamp, 2014; Uhnoo and Löfstrand, 2018) have commented on the scope of volunteers - both in police and non-police settings - to bring additional capacity, allowing officers to attend to more pressing needs, improve effectiveness, enhance performance, and increase agency ability to deliver services within (often shrinking) budgets. Indeed, respondents in Bullock's (2017: 346) study reflected on the deployment of police volunteers as a pragmatic response to economic reality', while an evaluation of a police volunteer scheme in Wales found that every one pound invested had a return of more than one pound, without factoring other benefits such as improved community cohesion and public confidence (Gravelle and Rogers, 2009). 
However, the volunteer contribution goes beyond cost saving measures or alleviating the burden of tasks on officers and staff. Volunteers can bring a range of skills and experiences to policing which enhance service provision and allow space for innovation and creativity (Brudney and Kellough, 2000; Mills et al., 2011; Dobrin and Wolf, 2016; Wolf et al., 2016). This can include specialist expertise - for example, around cyber or technology enabled crime (Hitchcock et al., 2017) - or local knowledge that may be limited amongst paid members of the workforce. Officers in Willis and Mastrofski's (2017) study highlighted the importance of detailed local knowledge of people, places, and customs, pointing to a specific skill set that volunteers - those that live in and have a 'history' with the area - can usefully contribute. Indeed, volunteers offer a valuable citizen perspective, creating opportunities for social interaction and connections with the community, which can, in turn, increase organisational efficiency and enhance accountability (Choudhury, 2010; Cordery et al., 2015; Wo et al., 2016).

\section{Challenges of Involving Volunteers in Policing}

However, involving volunteers in policing is not straightforward. Bullock (2014: 10) argues that extending policing and crime control related tasks beyond state actors is inherently problematic' and matching PSVs to suitable placements, difficult to achieve. The challenge of sourcing and delegating meaningful - rather than just 'busy' - tasks has been recognised across volunteering more broadly (Shin and Kleiner, 2003). These challenges are compounded in policing, which, in a UK context, has been the subject of criticism for 'mission creep', and accusations of backfilling previously paid roles with voluntary positions (Unison, 2014, 2018). Indeed, the cost saving contribution of PSVs is a controversial issue, with UK guidance clearly indicating that voluntary activity (of any kind) should not substitute paid work (Compact, 2005; 
Larson et al., 2011; Bullock and Leeney, 2014). It has been argued that volunteers should bring additionality to police services, rather than being central to or supplementing them; however, there is suggestion that lines between roles conducted by paid staff and volunteers have become blurred in places (Bullock, 2017). Furthermore, although an attractive option during times of fiscal restraint, delivering effective volunteering programmes is not cost-free, requiring considerable infrastructure investment (Brudney and Kellough, 2000; Hucklesby and Corcoran, 2016; Wolf et al., 2016). Brudney (2000) argues that involving volunteers should be focused on cost effective use of resources to complement existing service delivery, rather than saving money $-\mathrm{a}$ fallacy due to the funding required in order to reap benefits.

\section{The PSV Contribution and Volunteer Satisfaction}

Understanding the skills that volunteers bring, and creating meaningful placements that provide opportunities to use these skills, holds significant implications for satisfaction and morale

(Bullock, 2014; Callendar et al., 2019). The importance of contribution to volunteers' perceptions of their role has been noted in broader studies, with volunteers across a range of sectors attaching considerable meaning to feeling useful, seeing how they contribute to the priorities and mission of the organisation, and feeling that their time is well spent and worthwhile (Wisner et al., 2005; Alfes et al., 2017). In their study of volunteers in sports setting, Bang and Ross (2009) found that event volunteers expressed greater satisfaction when they felt they had helped to make the event a success. This has ongoing benefits for the organisation with the authors arguing that volunteer performance improves when they feel truly needed and responsible for tasks. Failing to offer satisfying and rewarding opportunities, or allow volunteers to use skills and fulfil motivations, has been linked 
to a negative impact on intention to remain a volunteer - both within policing organisations and broader volunteering contexts (e.g., Wisner et al., 2005; Alfes et al., 2017).

\section{Methodology}

This article is based on a survey conducted with PSVs in a large urban police service in England in 2015. The survey included a mixture of closed and open-ended questions exploring PSVs' attitudes and opinions around their role, relationships with others, and the future of volunteering in the police service. A number of survey questions used a Likert scale in which respondents indicated the strength to which they agreed or disagreed with a series of statements around their tasks, supervision and support, general feelings about their role, being part of a team, being involved, and feeling valued. Prior to being disseminated to potential respondents, the survey was piloted with a small sub-sample $(n=5)$ of PSVs to ensure clarity of questions, consistency of response options, and inclusion of suitable demographic measures. A link to the online survey (with a paper-based version available on request) was sent to the force email addresses of all $(n=1,047)$ PSVs in the force via the volunteer programme manager in April 2015. In a bid to improve the response rate, this was followed up with a reminder sent to both force and (where the volunteer programme manager had permission to do so) personal email addresses three weeks later. Contact with the PSVs was only possible through the force volunteer programme manager who, due to other projects ongoing at the time of fieldwork, was unable to send any further reminders.

The survey received 140 responses (139 online and one paper completion), representing 13 per cent of total PSVs in the force at that time. Survey responses were extracted from the online platform into SPSS to allow easier data management. Given the sample size and spread of data across response categories, frequencies and cross-tabulations were deemed to be the most 
appropriate type of analysis to conduct. Qualitative freetext responses were analysed thematically and presented as quotes (with pseudonyms to protect anonymity of participants), and helped to 'unpack' patterns emerging through closed ended questions. The survey attracted a notably older, female, white cohort of PSV respondents with almost half $(48 \%, n=56 / 117)$ aged 65 years or older, almost two-thirds $(61 \%, n=70 / 115)$ female, and the majority $(82 \%$, $n=96 / 117$ ) defining their ethnic group as white (British, Irish, any other white background). Over a third $(37 \%, n=42 / 113)$ of respondents were educated to degree level or equivalent. Given the older age profile of the survey cohort, it was unsurprising that the largest category of 'work status' responses were 'retired' $(58 \%, \mathrm{n}=67 / 115)$. In terms of PSV 'service', over half $(57 \%, n=70 / 122)$ of survey respondents had volunteered for three years or more (classified in this study as 'long term volunteers'), and half $(50 \%, \mathrm{n}=61 / 122)$ gave on average more than twenty hours per month to their role. Available data for all PSVs in the force at the time of fieldwork pointed to comparable proportions overall in terms of gender and length of time in role; however, a slight over representation of white PSVs, and those aged 65 years and over in the survey sample (albeit in line with previous studies (e.g., Britton et al., 2018; Millie, 2019) which consistently report an older PSV profile). While it is not possible to ascertain the extent to which the sample was representative of broader PSV experiences (nor, of course, the views of PSV 'leavers' which may differ considerably from those who have chosen to remain), the data presents useful insights in to the experiences of some PSVs - an important addition to a currently under researched space.

Thematic analysis, most notably responses to an open-ended question around volunteer role description, and two closed-ended questions asking respondents to rank their reasons for initially becoming and continuing to be a PSV from a set list (extracting the highest ranked reason for analysis), informed the development of two typologies based around PSV 
motivations and role types, and these were used to frame parts of analysis throughout the study. Motivation and role type embody dimensions of the volunteer experience that individuals attach importance to, and have been identified as significant enablers or inhibitors of sustained volunteerism; therefore, offered an insightful lens through which to view data (Omoto and Snyder, 2002; Penner, 2002; Chambre and Einholf, 2011). In terms of motivation, three categories of The Altruistic PSV (those driven by a desire to make a positive difference and 'give back' to the police service or community), The Social PSV (those seeking something interesting or exciting to do in their free time, or a chance to meet new people), and The Career PSV (those keen to pursue personal development goals to enhance their employability - either in the police service or other fields) emerged from the data. Role types were classified as The Operational PSV (those that a police officer may have some involvement in conducting or supporting e.g., CCTV operators, front counter services, police cadet staff) and The NonOperational PSV (those considered less likely to involve police officer support, and usually carried out by police staff, exclusively volunteers, or not at all without the involvement of a volunteer e.g., administration, some non-operational special interest roles, quality call backs, and community led consultation or discussion panels).

There was a fairly even split in terms of role typologies, although skewed slightly towards operational roles (The Operational PSV accounted for $58 \%(\mathrm{n}=76 / 132)$ of the sample, with the remaining $42 \%(n=56 / 132)$ of respondents defined as The Non-Operational PSV). In terms of motivations, The Altruistic PSV was the most prominent cohort, with almost two-thirds $(65 \%$, $\mathrm{n}=87 / 133$ ) of survey respondents defining their motivations as such. This was followed by The Social PSV $(24 \%, \mathrm{n}=32 / 133)$ and The Career PSV $(11 \%, \mathrm{n}=14 / 133)$. These trends mirror themes from broader studies of volunteering with altruism generally seen to be amongst the most prominent and sustainable drivers of helping behaviours (Penner and Finkelstein, 1998; 
Laverie and McDonald, 2007). However, motivations have been recognised as multidimensional, combining elements of both other- and self-interest (Wilson and Musick, 1997; Dolnicar and Randle, 2007; Rochester et al., 2012). Studies of police volunteers - in particular, Special Constables - report similar findings, with Ramshaw and Cosgrove (2019) referring to dualistic pathways incorporating both altruistic and egoistic motivations.

\section{Results}

\section{The PSV Contribution}

PSVs were asked to state in their own words what they thought their contribution was as a volunteer in policing. This often spanned multiple areas and touched on the range of tasks that they undertake - administration, training, providing specialist skills, and improving quality of service for the public - reflecting the diversity of volunteer contribution also noted across broader cohorts (Omoto and Snyder, 1995; Finkelstein, 2008). Despite this variance, three clear themes emerged: 'freeing up officer and staff time'; 'serving the community'; and 'contributing skills and time'. Table 1 presents each of these contribution categories alongside the role and motivations typologies.

Table 1: PSV role type, motivations, and perceived contribution

\begin{tabular}{|c|c|c|c|c|}
\hline \multirow[b]{2}{*}{$\begin{array}{c}\text { Role type and initial } \\
\text { motivation }\end{array}$} & \multirow[b]{2}{*}{ Total * } & \multicolumn{3}{|c|}{ Perceived contribution** } \\
\hline & & $\begin{array}{c}\text { Freeing up } \\
\text { officer/staff } \\
\text { time }\end{array}$ & $\begin{array}{l}\text { Serving the } \\
\text { community }\end{array}$ & Skills/time \\
\hline $\begin{array}{l}\text { The Operational } \\
\text { PSV }\end{array}$ & $\mathrm{n}=76 / 132$ & $n=42 / 69$ & $n=29 / 69$ & $\mathrm{n}=6 / 69$ \\
\hline $\begin{array}{l}\text { The Non- } \\
\text { Operational PSV }\end{array}$ & $\mathrm{n}=56 / 132$ & $n=29 / 56$ & $\mathrm{n}=11 / 56$ & $n=13 / 56$ \\
\hline Total & - & $n=71 / 125$ & $n=40 / 125$ & $n=19 / 125$ \\
\hline The Altruistic PSV & $\mathrm{n}=87 / 133$ & $\mathrm{n}=41 / 81$ & $\mathrm{n}=30 / 81$ & $\mathrm{n}=12 / 81$ \\
\hline
\end{tabular}




\begin{tabular}{|c|c|c|c|c|}
\hline The Social PSV & $\mathrm{n}=32 / 133$ & $n=20 / 29$ & $n=7 / 29$ & $n=6 / 29$ \\
\hline The Career PSV & $\mathrm{n}=14 / 133$ & $\mathrm{n}=12 / 13$ & $\mathrm{n}=0 / 13$ & $n=0 / 13$ \\
\hline Total & - & $n=73 / 123$ & $n=37 / 123$ & $n=18 / 123$ \\
\hline
\end{tabular}

*Proportion of all survey respondents

** Contribution categories were not mutually exclusive. Respondents frequently gave multiple responses; therefore proportions do not equate to $100 \%$.

\section{Freeing Up Officer and Staff Time}

Freeing up officer and staff time, often by undertaking tasks that respondents felt they (particularly warranted officers) should not have to do (such as administration) was the most frequently cited contribution by PSVs. The Operational PSV was more likely to view their contribution in terms of freeing up officer and staff time compared to The Non-Operational $\operatorname{PSV}(61 \%, \mathrm{n}=42 / 69$ vs. $52 \%, \mathrm{n}=29 / 56)$ - likely driven by the front counter volunteers that formed the majority of this cohort $(74 \%, n=56 / 76$ of all operational PSVs held front counter roles).

Turning to motivation typologies, themes of freeing up officer and staff time were particularly prevalent amongst The Altruistic PSV cohort (51\%, n=41/81). PSV Jonah, an operational PSV who identified his initial motivations as altruistic stated: 'I would like to think that the work I do can release other police officers to be on the street providing reassurance and help to the community' (Jonah, operational, altruistic, male, over 65 years, long term volunteer), while PSV Musa felt that his service '....allows officers to do what they were trained to do. Most officers did not sign up to work on a computer or prepare and file reports' (Musa, nonoperational, altruistic, male, over 65 years, long term volunteer). In line with the broader 'helping behaviours' of The Altruistic PSV, their contribution of freeing up officer and staff 
time was an opportunity to 'do good', taking on burdensome tasks, which they thought would enable officers and staff to better serve the community.

Freeing up officer and staff time also featured notably amongst The Career PSV cohort with almost all $(n=12 / 13)$ defining their contributions as such. PSV Marie argued that "with the support of the volunteers I know that our community will have extra police officers on the streets' (Marie, operational, career, female, 45-54 years, long term volunteer), while PSV Nella reflected on the contribution of volunteers as an opportunity to 'save time for an ever dwindling and overworked police staff' (Nella, non-operational, career, female, 45-54 years, long term volunteer). Although the motivations of The Altruistic PSV and The Career PSV fundamentally differed, the contribution of freeing up officer and staff time served distinct functions for each. For The Career PSV, this was perhaps a chance to gain skills by undertaking tasks that were previously related to paid (and arguably more meaningful or 'valid') roles, develop their CV, and improve chances of future paid employment.

\section{Serving the Community}

Providing a service to the public and serving the community was the next most frequently cited contribution identified by PSVs. The Operational PSV featured prominently here with proportionately more highlighting their contribution in this vein compared to The NonOperational PSV (42\%, $\mathrm{n}=29 / 69$ vs. $20 \%, \mathrm{n}=11 / 56)$ - again, likely related to the dominance of operational PSVs in front counter roles who often viewed their position in terms of providing an enhanced - or, in some cases, any - service to the public.

Themes of service were also prevalent in free text comments - particularly from The Altruistic $P S V$ who featured notably in this contribution category - perhaps unsurprising given the 
broader desires of this cohort to make a positive difference and 'give back'. PSV Fiona spoke about providing a service that might otherwise have been withdrawn in the absence of volunteers: 'My contribution as a volunteer is vital as the front door of the station is open to the public....No volunteers, no open door' (Fiona, operational, altruistic, female, 55-64 years, long term volunteer). Being a friendly and approachable presence featured within this theme. PSV Shivali spoke about helping to 'keep front counters accessible and operated by 'ordinary' and non-uniformed local residents' (Shivali, operational, altruistic, female, over 65 years, long term volunteer). Promoting community engagement also emerged here. Front counter volunteer Karen saw this as a 'two way street... a good way for volunteers to get to know what their local police station does and for officers to have an extra pair of hands' (Karen, operational, social, female, 35-44 years, long term volunteer). Indeed, volunteering can provide an opportunity for the public to engage with the local police service (and vice versa), and for PSVs themselves to act as a conduit for further engagement. Volunteering 'enables us to see behind the scenes and see how the police service makes our community a safer place to live' according to PSV Monica (Monica, altruistic, female, 55-64 years, short term volunteer, role type not stated), while PSV Patricia commented on the role of volunteers in showcasing the pluralised nature of policing services: 'It is essential that the community sees the police engaging with all areas, and that you do not have to be a paid member of staff to support the community' (Patricia, social, non-operational, female, 55-64 years, volunteer service length not stated). This points to a contribution that goes beyond the 'extra pair of hands' that PSV Karen referred to, with the PSV presenting a different capability to that of the paid workforce, enabled by their 'community status'.

\section{Contributing Skills and Time}


Offering skills and time to the police service was a lesser-cited contribution overall with nonoperational $(n=13 / 56)$ and altruistic PSVs $(n=12 / 81)$ the most likely of the cohort to make reference to these (compared to their operational, social, and career focused counterparts). However, the assets that PSVs bring from their professional and personal 'worlds' commercial, technical, or interpersonal skills that may not be present amongst the paid workforce - did come across clearly.

PSV Michelle spoke about volunteers bringing:

...experience of the commercial world and customer service which many police officers don't have. Many police understandably see themselves as a force rather than a service...the volunteer can help bring an element of service at the front counter (Michelle, operational, altruistic, female, over 65 years, long term volunteer).

PSV Anthony reflected on the capacity of volunteers to bring technical or interpersonal skills to a financially stretched organisation, again drawing back to the theme of freeing up officer or staff time:

Volunteers allows the [named force] to draw on the vast experience of members of the community to help in the fight against crime. In my case these are specialist technical skills. Others may be interpersonal skills. That means that officers can be out on patrol rather than at the front desk (Anthony, non-operational, altruistic, male, 45-54 years, short term volunteer).

However, the perceived 'time and skill' contribution of PSVs went beyond the addition of tangible, practical skills that were lacking in the paid workforce. They also felt they could bring 
'fresh ideas to the table and a new perspective' (Matilda, non-operational, female, long term volunteer, motivation and age not stated), 'experience of life' (Stella, operational, altruistic survey respondent, female, over 65 years, long term volunteer), and 'a different view of everyday events' (Jocelyn, non-operational, altruistic, female, over 65 years, long term volunteer). For some PSVs it was their personal demographics - sometimes underrepresented in the paid workforce - that enabled them to deliver a unique and enhanced service: 'I feel like I can really sit and listen to them...because I'm closer in age than some of the other officers' (Zoe, operational, career PSV, female, 22-24 years, long term volunteer). At the other end of the age spectrum, PSV Bruce commented on his role as part of a quality call back team: '...people respond positively when I call them as there is more empathy than a young police officer could generate' (Bruce, non-operational, altruistic PSV, male, over 65 years, volunteer service length not stated). This dual status - an 'outsider' view from 'inside' the organisation

- brings a unique volunteer 'offer', particularly in terms of community engagement, an alternative perspective, and PSVs being less shackled by institutional bureaucracy inherent within the paid workforce.

\section{The Importance of Being Useful}

PSVs in this study attached considerable meaning to being useful, understanding how they contribute to the organisation, and feeling that their time is well spent. These themes have been reflected elsewhere with the importance of meaningful taskings that usefully add to organisational goals, and provide opportunities for growth and development - and the consequences of failing to offer this in terms of volunteer satisfaction and longevity highlighted in broader volunteering literature (e.g., Penner, 2002; Jamison, 2003; Wisner et al., 2005; Alfes et al., 2017) and the limited studies focusing on police volunteering - both PSVs 
(e.g., Callender et al., 2018b; Millie, 2019), and Special Constables (e.g., Gaston and Alexander, 2001; Whittle, 2014).

Responses to a series of survey statements indicated that PSVs were positive about the tasks they undertook and contribution they felt able to make. The majority agreed (binary analysis, excluding 'neither agree nor disagree' responses which ranged between 10 and 23 respondents) that the tasks they did were interesting $(98 \%, n=119 / 122)$, that they were clear about the purpose of their role $(100 \%, n=119 / 119)$, the priorities of their team $(98 \%, n=108 / 110)$, and the force as a whole $(95 \%, \mathrm{n}=103 / 108)$, and thought they helped their team $(98 \%, \mathrm{n}=113 / 115)$, the force $(99 \%, n=119 / 120)$, and the community $(100 \%, n=113 / 113)$, with little divergence by role or motivation typology.

However, despite these largely positive views, feelings about having enough to do and being able to 'give' as much as they would like to were notably less certain areas. Indeed, although still representing a sizable majority $(83 \%, n=93 / 112)$ the proportion of respondents who agreed that they were used effectively most of the time was notably lower than the statements above. Some of the largest differences were to statements around volume of tasks: almost half (49\%, $\mathrm{n}=52 / 106$ ) of respondents agreed with the statement 'I am not given enough tasks to do', while, in a similar vein, only six per cent $(n=7 / 110)$ agreed that they were given too many tasks to do. This data also indicated some variation in PSVs' feelings about their contribution by role and motivation typology (see table 2).

Table 2: PSV role type, motivation, and feelings about tasks

\begin{tabular}{|c|c|c|c|c|}
\hline $\begin{array}{c}\text { Role type and } \\
\text { motivation }\end{array}$ & Total* & $\begin{array}{c}\text { Used } \\
\text { effectively }\end{array}$ & $\begin{array}{c}\text { Do not have } \\
\text { enough tasks } \\
\text { (Binary agree) }\end{array}$ & $\begin{array}{c}\text { Satisfied in role } \\
\text { (Binary agree) }\end{array}$ \\
\hline
\end{tabular}




\begin{tabular}{|c|c|c|c|c|}
\hline & & $\begin{array}{c}\text { (Binary } \\
\text { agree })\end{array}$ & & \\
\hline $\begin{array}{c}\text { The Operational } \\
\text { PSV }\end{array}$ & $\mathrm{n}=76 / 132$ & $\mathrm{n}=50 / 63$ & $\mathrm{n}=32 / 61$ & $\mathrm{n}=53 / 61$ \\
\hline $\begin{array}{c}\text { The Non- } \\
\text { Operational PSV }\end{array}$ & $\mathrm{n}=56 / 132$ & $\mathrm{n}=40 / 46$ & $\mathrm{n}=19 / 42$ & $\mathrm{n}=41 / 48$ \\
\hline Total & - & $n=90 / 109$ & $n=51 / 103$ & $n=94 / 109$ \\
\hline $\begin{array}{c}\text { The Altruistic PSV } \\
\text { The Social PSV }\end{array}$ & $\mathrm{n}=87 / 133$ & $\mathrm{n}=62 / 74$ & $\mathrm{n}=35 / 70$ & $\mathrm{n}=64 / 73$ \\
\hline The Career PSV & $\mathrm{n}=14 / 133$ & $\mathrm{n}=11 / 12$ & $\mathrm{n}=6 / 9$ & $\mathrm{n}=20 / 25$ \\
\hline Total & - & $n=90 / 109$ & $n=52 / 104$ & $n=93 / 108$ \\
\hline
\end{tabular}

* Proportion of all survey respondents

The Operational PSV was proportionately slightly less likely to feel that they were used effectively in their role $(79 \%, n=50 / 63$ vs. $87 \%, n=40 / 46)$, and slightly more likely to agree that they did not have enough tasks to do $(52 \%, \mathrm{n}=32 / 61$ vs. $45 \%, \mathrm{n}=19 / 42)$ compared to The Non-Operational PSV. Turning to motivation typologies, The Career PSV was the most likely to feel that they were used effectively across both initial and continuing motivations, and The Social PSV the least likely $(92 \%, \mathrm{n}=11 / 12$ vs. $74 \%, \mathrm{n}=17 / 23)$. There was little difference in terms of not having enough tasks to do; although The Social PSV was amongst the least likely of the motivation typologies to agree that they didn't have enough tasks to do, perhaps indicating that volume of tasks is less important to this type of motivated volunteer.

There are certain implications of not having enough to do (table 3). PSVs who agreed that they were used effectively were considerably more likely to feel satisfied in their roles and less likely to agree that they did not have enough tasks to do, compared to those who did not feel 
that they were used effectively. Those who agreed that they were not given enough to do were less likely to state that they felt they were used effectively and less likely to feel satisfied in their roles compared to those who disagreed with this statement, while almost all survey respondents who felt satisfied in their role agreed that they were used effectively compared to just a fifth who were not satisfied. Furthermore, those who felt satisfied in their role were considerably less likely to agree that they did not have enough tasks to do.

Table 3: Feelings about tasks

\begin{tabular}{|c|c|c|c|}
\hline Feelings about tasks & $\begin{array}{c}\text { Used } \\
\text { effectively } \\
\text { (Binary agree) }\end{array}$ & $\begin{array}{c}\text { Do not have } \\
\text { enough tasks } \\
\text { (Binary agree) }\end{array}$ & $\begin{array}{c}\text { Satisfied in } \\
\text { role } \\
\text { (Binary agree) }\end{array}$ \\
\hline Used effectively (Binary agree) & - & $\mathrm{n}=24 / 75$ & $\mathrm{n}=80 / 82$ \\
\hline Used effectively (Binary disagree) & - & $\mathrm{n}=16 / 18$ & $\mathrm{n}=5 / 13$ \\
\hline Do not have enough tasks (Binary agree) & $\mathrm{n}=24 / 40$ & - & $\mathrm{n}=26 / 36$ \\
\hline Do not have enough tasks (Binary & $\mathrm{n}=51 / 53$ & - & $\mathrm{n}=45 / 48$ \\
\hline disagree) & & $\mathrm{n}=26 / 71$ & - \\
\hline Satisfied in role (Binary agree) & $\mathrm{n}=80 / 85$ & $\mathrm{n}=10 / 13$ & - \\
\hline
\end{tabular}

Frustration at not having an adequate supply of suitable tasks and opportunities to usefully contribute to policing was a theme infused throughout responses to open ended questions. When asked about the negatives of volunteering, although the most common response was 'nothing', the next most frequently cited issue was linked to not having enough to do, with respondents referring to a 'lack of suitable tasks' (Kyran, operational, altruistic, male, over 65 years, short term volunteer), 'not being able to do more' (Darinka, operational, social, female, over 65 years, long term volunteer), and 'wasting time with absolutely nothing to do and no one to go to to find out anything' (May, non-operational, social, female, 55-64 years, long term volunteer). Some felt that PSVs' time was wasted on trivial tasks, or tasks which were not 
equivalent to their skills and experience. As PSV Phillip stated 'lots of enthusiasm and talent being wasted on trivial tasks' (Phillip, non-operational, altruistic, male, over 65 years, short term volunteer), while PSV Sebastian referred to volunteers who 'in their other life were experts in different fields and I can't help feeling that this is wasted' (Sebastian, operational, social, male, over 65 years, long term volunteer), and PSV Aaliyah commented on 'loving my volunteering role' but feeling that 'it could be so much more' (Aaliyah, non-operational, altruistic , female, 35-44 years, long term volunteer). PSV Lily drew attention to the need for the service itself to find ways to make best use of volunteers: 'The skills of volunteers are many and varied. The [named force] would benefit if it could find a way of utilising these skills more effectively' (Lily, operational, social, female, over 65 years, long term volunteer). Making better use of volunteer skills and experience, ensuring suitable tasks are available, and placing volunteers in roles where they can be most appropriately involved was important to PSVs in this study - it was not simply about being 'busy'.

Contributing meaningfully in their role was influential in PSVs' decisions to continue volunteering. While no PSVs stated definitively that they were planning to leave their role, a minority of respondents $(n=13 / 117)$ were unsure about their intentions to continue volunteering - the primary driver for which was not having enough suitable tasks or being unable to make the contribution they hoped. Indeed, those respondents who were unsure about their intention to continue volunteering were proportionately less likely to state that they were used effectively, more likely to agree that they were not given enough tasks to do, and less likely to feel satisfied in their roles, compared to those who intended to continue volunteering. PSV Annie stated: 'I am getting very bored. We've had so much work taken away from us...we are left with hardly anything to do without getting an officer to deal with the problem' (Annie, non-operational, social, female, over 65 years, volunteer service length not stated), while PSV 
Pearl commented: 'I have other projects which I wish to pursue and cannot afford to constantly sit in an office doing nothing' (Pearl operational, altruistic, female, over 65 years, long term volunteer). Failing to provide satisfying and rewarding tasks, or opportunities to use skills and fulfil motivations, clearly had a negative impact on PSVs' enthusiasm, commitment, and intention to remain a volunteer - a theme that has been reflected in broader volunteering literature, and studies within policing contexts (e.g., Wisner et al., 2005; Alfes et al., 2017; Ramshaw and Cosgrove, 2019).

\section{Discussion and Conclusion}

This article has explored the roles that PSVs occupy and the tasks they undertake - a diverse assemblage including administration, operational support, community facing services, and special interest functions. The descriptions that PSVs in this study gave of contributions they felt they made through these roles pointed to three clear themes: freeing up officer and staff time; serving the community; and contributing skills and time. Analysis by role and motivation typology highlighted the heterogeneity within PSV cohorts, underlining the importance of a research approach that recognises difference, rather than assuming a single, generic PSV experience.

While PSVs in this study presented largely positive views around the tasks they undertook and the contribution they made, there was more uncertainty around feeling used effectively or having enough to do. The Operational PSV was generally less likely to agree that they were used effectively, and more likely to agree that they did not have enough tasks. With front counter service volunteers featuring heavily within this typology, these findings may reflect footfall in some front counters, or heightened expectations of anticipated contribution that operationally focused PSVs may hold - which prove challenging to meet within an 
environment that sometimes struggles to task volunteers. It was often The Career PSV that featured within notable divergent trends, with PSVs in this motivation category amongst those feeling like they were used most effectively. Again, it was difficult to identify the factors underlying this. However, The Career PSV may be less likely to continue volunteering (and, therefore, would not feature in this study sample) if the role does not serve their needs (including the contribution they hope to make), perhaps reflecting the more focused nature of career or personal development type motivations, rather than broader 'helping' tendencies or social goals of The Altruistic PSV and The Social PSV. Similar themes are present in broader volunteering literature, with motivation fulfilment shown to be influential on satisfaction and volunteers' decisions to continue to give their time (Clary et al, 1998; Omoto and Snyder, 2002; Chambre and Einholf, 2011).

While themes emerged around perceptions of contribution by role and motivation typology, some of the strongest patterns were seen within these 'feelings about tasks' variables with PSVs who agreed that they were used effectively considerably more likely to feel satisfied in their roles, and less likely to agree that they did not have enough tasks to do, compared to those who did not feel that they were used effectively - a trend that remained consistent throughout crosstabulation of the other two survey statement responses (i.e., those who agreed that they were not given enough to do were less likely to state they were used effectively and less likely to feel satisfied etc.). Furthermore, the small proportion of PSVs in this study who were unsure about their future volunteering intentions were less likely to feel that they were used effectively, more likely to agree that they were not given enough tasks to do, and less likely to be satisfied in their roles. Indeed, the tasks that PSVs undertook and the contribution they felt able to make held great meaning, and were influential on feelings of satisfaction and their intention to continue volunteering - themes that have been clearly reflected in other studies of police 
volunteering (e.g., Gaston and Alexander, 2001; Callender et al., 2018b; Millie, 2019) and broader not-for-profit spaces (e.g., Penner, 2002; Jamison, 2003; Wisner et al., 2005; Alfes et al., 2017).

A sense of feeling underused, having additional capacity, and wanting to contribute more amongst PSVs in this study perhaps throws some doubt on the suggestion that the police are relying increasingly on PSVs in times of austerity. It is undeniable that some PSVs are undertaking roles that previously were (indeed, still are in some locations) carried out by warranted officers or paid staff - most notably on police station front counters. However, the sample in this study does not overwhelmingly point to PSVs neatly 'slotting in' to roles that were previously held by officers and staff. Indeed, some were struggling to fill the time that they freely gave to the police service. As outlined earlier, the challenges of deploying volunteers to meaningful tasks that fulfil their desire to contribute usefully to the organisation have been recognised across broader volunteering realms (e.g., Shin and Kleiner, 2003), with additional barriers in a policing context which has faced criticism around accusations of filling previously paid roles with voluntary positions (Unison, 2014, 2018).

Policing routinely operates 'under conditions of fast-paced and multidimensional change' (Higgins et al., 2017:5) - rapidly shifting priorities around threat, harm, and risk, and shrinking budgets - each of which holds implications for how PSVs are involved in policing. A changing landscape and more stringent fiscal restrictions - the impact of which are still felt across policing despite a more generous Spending Round in 2019 - have required forces to reconsider their priorities and more realistically align these with available resources (Millie, 2014; HM Treasury, 2019; Police Superintendents' Association, 2019). The PSV role presents robust opportunities here, offering space for creativity and innovation. This requires a fresh approach 
- one that explores potential of the role beyond traditional organisational structures (Britton and Knight, 2016). Indeed, the processes and patterns of 'being' a volunteer do not have to mirror those of paid officers and staff. Episodic stints of volunteering, relying on a registered bank of individuals or companies willing to share their (or their staff's) time and skills during periods of demand or when workloads require specialist knowledge which may not be available in the paid workforce (e.g., languages, financial knowledge, IT expertise, local knowledge, or an enhanced ability to engage with the public beyond that of the uniformed officer), could prove particularly fruitful in a police environment where tasks are becoming increasingly global and complex in nature. Effects of the Policing Education Qualifications Framework (PEQF) should also be considered here. With degree level entry requirements for police officers, gained through pre-application study or on-the-job apprenticeships, potentially influencing a would-be PSVs' (particularly those driven by career motivations and using volunteering as an initial mode of experience to help secure employment in the police at a later date) decision to volunteer, it is increasingly pertinent that there is greater clarity and creativity around PSV roles and tasks.

The recent Policing and Crime Act 2017, allowing chief officers to confer a range of powers to PSVs (excluding those in a core list reserved for warranted officers), presents an opportune time to reconsider the involvement of PSVs - and, perhaps, start to reimagine their role in policing. To do this, requires a level of investment from forces - both financial (albeit to a lesser degree than the salaried workforce) and strategic - to foster an environment in which PSVs are recognised, valued, able to develop, and contribute to both existing operating models and new directions in policing practice (Callender et al., 2019). Failure to prioritise such issues of leadership and infrastructure risks reputation of both volunteers and the police organisation, 
and the contribution that PSVs can make as police services continue to navigate their way through challenging climates.

\section{Acknowledgements}

The authors would like to thank the Police Support Volunteers who generously gave their time to be part of this study. Thanks also to the anonymous reviewers for their helpful comments on an earlier draft of this article.

\section{References}

Alfes, K., Antunes, B. and Shantz, A. (2017). 'The Management of Volunteers - What Can Human Resources Do? A Review and Research Agenda.' The International Journal of Human Resource Management, 28 (1): 62-97.

Bang, H., and Ross, S. (2009), 'Volunteer Motivation and Satisfaction.' Journal of Venue and Event Management, 1: 61-77.

Britton, I. and Callender, M. (2018). 'Strategic Direction and Leadership in the Special Constabulary.' In Bullock, K. and Millie, A. (eds), The Special Constabulary: Historical Context, International Comparison, and Contemporary Themes. Abingdon: Routledge, pp. $149-168$

Britton, I. and Knight, L. (2016). 2030 Vision: Specials and Police Support Volunteers - At the Heart of Policing Reform. Northampton: Institute for Public Safety, Crime and Justice. 
Britton, I., Knight, L. and Lugli, V. (2018). 2018 Benchmarking Exercise Northampton: Institute for Public Safety, Crime and Justice.

Brudney, J. (2000). 'The Effective Use of Volunteers: Best Practice for the Public Sector.' Law and Contemporary Problems, 62 (4): 219-255.

Brudney, J. and Kellough, J. (2000). 'Volunteers in State Government: Involvement, Management, and Benefits.' Nonprofit and Voluntary Sector Quarterly, 29 (1): 111-130.

Bullock, K. (2017). 'Shoring Up the 'Home Guard'? Reflections on the Development and Deployment of Police Support Volunteer Programmes in England and Wales.' Policing and Society: An International Journal of Research and Policy, 27 (4): 341-357.

Bullock, K. (2014). Citizens, Community and Crime Control. Hampshire: Palgrave Macmillan.

Bullock, L. and Leeney, D. (2014). 'On Matters of Balance: An Examination of the Deployment, Motivation and Management of the Special Constabulary.' Policing and Society, 26 (5): 483-502.

Callender, M., Pepper, M., Cahalin, K. and Britton, I. (2019). 'Exploring the Police Support Volunteer Experience: Findings from a National Survey.' Policing and Society: An International Journal of Research and Policy, 29 (4): 392-406.

Callender, M., Cahalin, K., Cole, S., Hubbard, L. and Britton, I. (2018a). 'Understanding the Motivations, Morale, and Retention of Special Constables: Findings from a National Survey.' Policing: A Journal of Policy and Practice, Advanced Online Access. 
Callender, M., Cahalin, K., Britton, I. and Knight, L. (2018b). National Survey of Police Support Volunteers. Northampton: Institute for Public Safety, Crime and Justice.

Chambre, S. and Einolf, C. (2011). 'Who Volunteers? Constructing a Hybrid Theory.' Working Paper from the Selected Works of Christopher J Einolf. Illinois: DePaul University.

Choudhury, E. (2010). 'Attracting and Managing Volunteers in Local Government.' Journal of Management Development, 29 (6): 592-603.

Clamp, K. (2014). 'A Local Response to Community Justice Problems? A Critique of Community Justice Panels.' British Journal of Community Justice, 12 (2): 21-34.

Clary, E., Snyder, M., Ridge, R., Copeland, J., Stukas, A. Haugan, J. and Miene, P. (1998). 'Understanding and Assessing the Motivations of Volunteers: A Functional Approach'. Journal of Personality and Social Psychology, 74 (6): 1516-1530.

Compact (2005). Compact Code of Good Practice on Volunteering. Birmingham: Commission for the Compact.

Cordery, C., Smith, K. and Proctor-Thompson, S. (2015). 'Staff and Volunteers' Perceptions of the Volunteer Programme: An Alternative Use of the Nets Benefits Index.' Voluntary Sector Review, 6 (1): 173-191.

Dobrin, A. and Wolf, R. (2016). 'What is Known and Not Known about Volunteer Policing in the United States.' International Journal of Police Science and Management, 18 (3): 220-227. 
Dolnicar, S. and Randle, M. (2007). 'What Motivates Which Volunteers? Psychographic Heterogenity Among Volunteers in Australia'. Voluntas, 18: 135-155.

Finkelstein, M. (2008). 'Predictors of Volunteer Time: The Changing Contributions of Motive Fulfilment and Role Identity.' Social Behaviour and Personality, 36 (1): 1353-1363.

Frederickson, P. and Levin, D. (2004). 'Accountability and the Use of Volunteer Officers in Public Safety Organisations.' Public Performance and Management Review, 27 (4): 118-143.

Gaston, K. and Alexander, J. (2001). 'Effective Organisation and Management of Public Sector Volunteer Workers: Police Special Constables'. International Journal of Public Sector Management, 14 (1): 59-74.

Gravelle, J. and Rogers, C. (2009). 'Your Country Needs You! The Economic Viability of Volunteers in the Police.' Safer Communities, 8 (3): 34-38.

Higgins, A., Hales, G. and Chapman, J. (2017). Police Effectiveness in a Changing World: Luton Site Report London: The Police Foundation.

Hitchcock, A., Holmes, R. and Sundorph, E. (2017). Bobbies on the Net: A Police Workforce for the Digital Age. London: Reform.

HM Treasury (2019) Spending Round 2019 London: HM Government https://www.gov.uk/government/publications/spending-round-2019-document/spendinground-2019 (accessed 06/02/20). 
Hucklesby, A. and Corcoran, M. (2016). 'Introduction.' In Hucklesby, A. and Corcoran, M. (eds), The Voluntary Sector and Criminal Justice. Hampshire: Palgrave Macmillan, pp. 1-13.

Institute of Public Safety, Crime and Justice (IPSCJ) (2018). 2018 Benchmarking Exercise. Northampton: University of Northampton.

Jamison, I. (2003). 'Turnover and Retention Among Volunteers in Human Service Agencies'. Review of Public Personnel Administration, 23 (2): 114-132.

Larson, J., Lewis, V., Kay, K., and Kelso, C. (2011). 'Reducing the Cost of Crime through Reserve Police Officers and Volunteer Citizen Patrol.' Research in Business and Economics Journal, 3: 1-7.

Laverie, D. and McDonald, R. (2007), 'Volunteer Dedication: Understanding the Role of Identity Importance on Participation Frequency'. Journal of Macromarketing, 27: 274-288.

Millie, A. (2019). 'Citizens in Policing: The Lived Reality of Being a Police Support Volunteer.' Policing and Society: An International Journal of Research and Policy, 29 (4): 407-419.

Millie, A. (2014). 'What Are the Police For? Rethinking Policing Post-Austerity.' In Brown, J.M. (ed), The Future of Policing. Abingdon: Routledge, pp. 52-63. 
Mills, A., Meek, R. and Gojkovic, D. (2011). 'Exploring the Relationship Between the Voluntary Sector and the State in Criminal Justice.' Voluntary Sector Review, 2 (2): 193-211.

Morgan, R. (2012). 'Crime and Justice in the 'Big Society.' Criminology and Criminal Justice, 12 (5): 463-481.

National Audit Office (September 2018). Financial Sustainability of Police Forces in England and Wales 2018. London: National Audit Office.

Omoto, M. and Snyder, M. (2002). 'Considerations of Community: The Context and Process of Volunteerism.' American Behavioural Scientist, 45: 846-867.

Penner, L. (2002). 'Dispositional and Organisational Influences on Sustained Volunteerism: An Interactionist Perspective.' Journal of Social Issues, 58 (3): 447-467.

Penner, L. and Finkelstein, M. (1998). 'Dispositional and Structural Determinants of Volunteerism', Journal of Personality and Social Psychology, 74 (2): 525-537.

Police Superintendents' Association (2019) President's 2019 Conference Speech https://www.policesupers.com/2019/09/09/presidents-2019-conference-speech// (accessed $06 / 02 / 20)$.

Ramshaw, P. and Cosgrove, F. (2019). 'Changing Motivations of the Special Constable: A Qualitiative Analysis of the Role of Organisational Experience in Retaining Satisfaction and 
Commitment'. Policing and Society: An international Journal of Research and Policy, Advanced Online Access.

Ren, L., Zhao, J., Lovrich, N. and Gaffney, M. (2006). 'Participation Community Crime Prevention: Who Volunteers for Police Work?' Policing: An International Journal of Police Strategies and Management, 29 (3): 464-481.

Rochester, C., Ellis Paine, A. and Howlett, S. (2012). Volunteering and Society in the $21^{\text {st }}$ Century. Hampshire: Palgrave Macmillan.

Shin, S. and Kleiner, B. (2003). 'How to Manage Unpaid Volunteers in Organisations.' Management Research News, (26) 2/3/4: 63-71.

Steden, R., van Caem, R. and Boutellier, H. (2011). 'The 'Hidden Strength' of Active Citizenship: The Involvement of Local Residents in Public Safety Projects.' Criminology and Criminal Justice, 11 (5): 433-450.

Uhnoo, S. and Löfstrand, C. (2018). 'Voluntary Policing in Sweden: Media Reports of Contemporary Forms of Police-Citizen Partnerships.' Journal of Scandinavian Studies in Criminology and Crime Prevention, 19 (1): 41-60.

Unison (2018). Crossing the Line Police Support Volunteers: Rising Numbers and Mission Creep. London: Unison. 
Unison (2014). Home Guard of Police Support Volunteers to Fill in for Staff Cuts. London: Unison.

Van Steden, R. and Mehlbaum, S. (2019). 'Police Volunteers in the Netherlands: A Study on Policy and Practice.' Policing and Society: An International Journal of Research and Policy, 29 (4): 420-433.

Whittle, J. (2014). 'The Rise of the Special Constabulary: are Forces Getting Value for Money from their Voluntary Officers? An Empirical Study in Avon and Somerset Police.' Police Journal: Theory, Practice and Principles, 87: 29-40.

Wilkins, T. (2008). 2008 Police Support Volunteer (PSV) Questionnaire. London: College of Policing.

Willis, J. and Mastrofski, S. (2017). 'Understanding the Culture of Craft: Lessons from Two Police Agencies.' Journal of Crime and Justice, 40 (1): 84-100.

Wilson, J. and Musick, M. (1997). 'Who Cares? An Integrated Theory of Volunteer Work'. American Sociological Review, 62: 694-713.

Wisner, P., Stringfellow, A., Youngdahl, W. and Parker, L. (2005). 'The Service Volunteer Loyalty Chain: An Exploratory Study of Charitable Not-For-Profit Service Organisations.' Journal of Operations Management, 23: 143-161. 
Wo, J., Hipp, J., and Boessen, A. (2016). 'Voluntary Organisations and Neighbourhood Crime: A Dynamic Perspective.' Criminology, 54 (2): 212-241.

Wolf, R., Holmes, S. and Jones, C. (2016). 'Utilisation and Satisfaction of Volunteer Law Enforcement Officers in the Office of the American Sheriff: An Exploratory Nationwide Study.' Police Practice and Research: An International Journal, 17 (5): 448-462. 